\title{
A INFLUÊNCIA NEOLIBERAL NAS POLÍTICAS EDUCACIONAIS BRASILEIRAS: UM OLHAR SOBRE A BNCC
}

\author{
THE NEOLIBERAL INFLUENCE ON BRAZILIAN EDUCATIONAL POLICIES: AN \\ OUTLOOK ON THE BNCC
}

\author{
Carolina de Moura Vasconcelos \\ Mestra em Educação - UEM \\ Universidade Estadual de Maringá - UEM. \\ Maringá, Paraná - Brasil \\ carolvasconcelos.uem@gmail.com \\ Carlos Henrique Ferreira Magalhães \\ Doutor em Educação - UFSCar \\ Universidade Estadual de Maringá - UEM. \\ Maringá, Paraná - Brasil. \\ chfmagalhaes@uem.br \\ Telma Adriana Pacifico Martineli \\ Doutora em Educação - UEM \\ Universidade Estadual de Maringá - UEM. \\ Maringá, Paraná - Brasil. \\ telmamartineli@hotmail.com
}

Resumo: O artigo tem como objetivo analisar a influência neoliberal na educação e seus reflexos na elaboração da Base Nacional Comum Curricular. Trata-se de um estudo bibliográfico e documental fundamentado no materialismo histórico e dividido em três partes principais: (1) A origem dos princípios neoliberais; (2) A influência desses princípios na origem e na estrutura da educação; (3) A dinâmica da relação entre os conceitos neoliberais e os princípios do aprender a aprender, das competências e habilidades e do protagonismo do aluno, presentes na BNCC. Dessa forma, o artigo teve como questionamento central: Qual a influência neoliberal na educação e quais são seus reflexos na elaboração da Base Nacional Comum Curricular brasileira? Conclui-se que o neoliberalismo enquanto corrente de pensamento e conjunto de políticas adotadas por governos neoconservadores surge a partir de um liberalismo econômico que culminou em inúmeras crises e necessitou de reformas econômicas. Esse processo de reformas é observado nas políticas brasileiras de privatização, de incentivo à competição, bem como na educação voltada para o mercado de trabalho. Portanto, os ideais neoliberais e os documentos dos organismos internacionais influenciaram a estruturação da BNCC que se orienta pelo aprender a aprender, para promover a formação de competências e habilidades, assim como o protagonismo do aluno no processo de ensino, o qual é permeado por esses princípios.

Palavras-chave: BNCC; educação; neoliberalismo.

\begin{abstract}
The article aimed to review the neoliberal influence on education and its repercussions in the development of the National Common Curricular Base (BNCC). This is a bibliographic and documentary study based on historical materialism, which was divided into three main parts: (1) The origin of neoliberal principles; (2) The influence of these principles on the origin and structure of education; (3) The dynamics of the relationship between neoliberal concepts and the principles of learning to learn, of the competences in the teaching process and the protagonism of the student present at the BNCC. This way, the central question of this article was: What is the neoliberal influence on education and its repercussions in the development of the National Common Curricular Base? We concluded that neoliberalism, as a chain of thoughts and set of policies taken up by neoconservative governments, emerges from an economic liberalism that culminated in countless crises and needed economic reforms. This reform process is observed in the Brazilian policies of privatization, incentive to competition and education aimed at the labor market. Therefore, neoliberal ideals and the documents of international organizations have influenced the establishment of the BNCC, which presents the learning to learn, the competencies in the teaching process and the student's protagonism permeated by these principles.
\end{abstract}

Keywords: BNCC; education; neoliberalism.

Para citar - (ABNT NBR 6023:2018)

VASCONCELOS, Carolina de Moura; MAGALHÃES, Carlos Henrique Ferreira; MARTINELI, Telma Adriana Pacifico. A influência neoliberal nas políticas educacionais brasileiras: um olhar sobre a BNCC. Eccos - Revista Científica, São Paulo, n. 58, p. 1-18, e10726, jul./set. 2021. Disponível em: https://doi.org/10.5585/eccos.n58.10726. 


\section{Introdução}

A produção histórica da humanidade explica o homem e a sociedade de determinada época, pois a sociedade se estrutura no modo como os homens produzem materialmente "[...] e desenvolvem suas atividades sob determinados limites, pressupostos e condições materiais [...]" (MARX; ENGELS, 1986).

$\mathrm{Na}$ sociedade capitalista, o modo de produção passou por vários estágios de desenvolvimento que se iniciam, no final do século XIX, e caracterizam-se pelo grande avanço científico, principalmente, com a inserção das máquinas e a modificação da produção manufatureira. Essas transformações têm se intensificado, especificamente a partir da década de 80 , com as teorias do imperialismo, o capital financeiro, a demanda e a concorrência. Os avanços tecnológicos são espaços de acumulação ocupados por agentes econômicos que utilizam o Estado como instrumento necessário para a exploração da classe trabalhadora (TAUILE; FARIA, 1999).

Engels (1984) afirma que o Estado capitalista atua como regulador das relações entre os proprietários do capital e os proprietários da força de trabalho. A classe dominante é hegemônica e tem seus interesses atendidos por esse Estado, o que permite adquirir novos meios de exploração da classe dominada.

$\mathrm{Na}$ contemporaneidade, os interesses da classe dominante são mantidos a partir dos ideais neoliberais produzidos nas transformações do capitalismo, as quais exigiram uma nova formação estatal com privatizações, desregulamentação das relações de trabalho, ajuste fiscal e monetário e desregulamentação do mercado (VIANA, 2008). A emergência do neoliberalismo foi uma resposta ao "[...] processo de crises do regime de acumulação anterior, sendo manifestação do novo regime" (VIANA, 2008, p. 4) que emergia com a necessidade de modificações para manter a relação social capitalista.

As constantes crises do sistema capitalista geraram as inúmeras reformas econômicas e políticas do estado brasileiro, principalmente a partir da década de 90. Segundo Gentili (1996) as crises atingem o sistema educacional, tendo a necessidade de implementar as medidas neoliberais para gerar eficiência, flexibilidade e eficácia na qualidade do ensino, a educação torna-se um instrumento de manipulação, em que por um processo ideológico hegemônico as classes trabalhadoras aceitam as condições de exploração necessárias para a sobrevivência do sistema capitalista. 
$\mathrm{Na}$ compreensão da concepção de mundo do estado capitalista e das influências neoliberais em sua ação, o objetivo deste artigo consistiu em analisar a influência neoliberal na educação e seus reflexos na elaboração da Base Nacional Comum Curricular (BNCC).

Este artigo se baseia no método de Marx, portanto, a reflexão a respeito da Base Nacional Comum Curricular (BNCC), promulgada em 2016 pelo governo Temer ${ }^{1}$, requer destacar a origem, a estrutura e a dinâmica desse documento, pois, de acordo com Paulo Netto (2009), o método de Marx busca partir da aparência do objeto para chegar a sua essência. Segundo o autor:

Alcançando a essência do objeto, isto é: capturando a sua estrutura e dinâmica, por meio de procedimentos analíticos e operando a sua síntese, o pesquisador a reproduz no plano do pensamento; mediante a pesquisa, viabilizada pelo método, o pesquisador reproduz, no plano ideal, a essência do objeto que investigou (PAULO NETTO, 2009, p. 5).

Desta forma, a compreensão acerca das influências neoliberais na educação, no âmbito da essência, ocorrerá por meio dos procedimentos analíticos descritos por Karl Marx (1857). José Paulo Netto (2009) e outros estudiosos do método materialista histórico explicam que esses procedimentos consistem em relacionar o objeto pesquisado com a totalidade das relações sociais, suas determinações econômicas, sociais e políticas e as contradições presentes. A análise parte da estrutura da sociedade capitalista e da dinâmica que fez emergirem os princípios neoliberais e a sua influência na educação mundial e brasileira. Especificamente, busca-se, no processo de elaboração da Base Nacional Comum Curricular (BNCC) e na sanção do documento pelo Estado, compreender a relação entre os conceitos do neoliberalismo e o "aprender a aprender", as "competências" e o "protagonismo do aluno", presentes no documento.

Com isso acredita-se que serão reunidos os fatos necessários para entender a singularidade da BNCC com a particularidade das políticas educacionais numa totalidade, cuja relação social é regida pelo Capital. Destacar conjuntamente as múltiplas determinações que sustentam a BNCC também constitui um procedimento necessário, a fim de termos clareza a respeito do projeto de homem e de sociedade que a BNCC, em consonância com a ideologia neoliberal, propõe a contribuir para sua formação.

O questionamento central que orientou a pesquisa foi: Qual a influência neoliberal na educação e quais são seus reflexos na elaboração da Base Nacional Comum Curricular? A síntese desta investigação é apresentada nos tópicos a seguir. 


\title{
1 As origens dos princípios neoliberais
}

A ascensão e o desenvolvimento do capitalismo foram processos de transformação contínuos e progressivos. A passagem do feudalismo para o capitalismo foi marcada por um grau máximo da divisão do trabalho e da invenção das máquinas. Nesse contexto, Adam Smith (1723-1790) viu a necessidade de explicar a sociedade não mais pela filosofia, mas pela economia política, visto que a sociedade se organizava em um novo modo de produção, o capitalista.

A divisão do trabalho facilitava o aumento das destrezas dos indivíduos e permitia a economia do tempo por não ser mais necessária a troca de funções; ademais, nesse processo, com a invenção das máquinas, o trabalho era facilitado e aumentava a produção. Desta forma, os trabalhadores necessitavam apenas de algumas operações simples, de modo que, para essas pessoas, a educação deveria focar as matérias mais essenciais como ler, escrever e calcular (SMITH, 1996).

Apesar de Smith compreender as relações pelas leis materiais, sua leitura de mundo possuía uma perspectiva burguesa. Rosa (2015) explica que as análises do autor estavam voltadas para a manutenção da sociedade capitalista, em uma perspectiva de atuação do Estado na educação com o propósito de obter vantagens das camadas inferiores e reproduzir o poder da burguesia, já que buscava por meio da instrução dos pobres a possibilidade de obter estabilidade e formar uma camada social com capacidades úteis para a reprodução do capitalismo. De acordo com Smith (1996, p. 246),

\begin{abstract}
[...] embora, as pessoas comuns não possam, em uma sociedade civilizada, ser tão bem instruídas como as pessoas de alguma posição e fortuna, podem aprender as matérias mais essenciais da educação - ler, escrever e calcular - em idade tão jovem, que a maior parte, mesmo daqueles que precisam ser formados para as ocupações mais humildes, têm tempo para aprendê-las antes de empregar-se em tais ocupações. Com gastos muito pequenos, o Estado pode facilitar encorajar e até mesmo impor a quase toda a população a necessidade de aprender os pontos mais essenciais da educação.
\end{abstract}

Nesta compreensão, os escritos de Adam Smith tornaram-se pedra fundamental do liberalismo no século XIX, por se aproximarem de correntes conservadoras necessárias à manutenção do estado capitalista, na perspectiva de redução do Estado, expansão do mercado e disseminação da educação utilitarista.

A adoção das políticas liberais no século XIX desencadeou crises de superprodução, pânicos financeiros e disputas entre grandes potências mundiais. Isso abriu o caminho para a implementação do Keynesianismo no século XX, de forma que o Estado passou a controlar o 
nível de atividade econômica, a fazer a manutenção de uma estrutura de bem-estar social e a implementar políticas sociais que diminuíam as desigualdades sociais (MORAES, 1997).

As ações da política de bem-estar social permitiram a reconstrução e o desenvolvimento do capitalismo em um período pós-guerra, mas, concomitantemente a esse processo, os ideais neoliberais se desenvolviam e aguardavam o momento propício para atuar nas ações políticas da sociedade. A construção de companhias multinacionais, que se espalhavam por todo o mundo, e o desenvolvimento do mercado financeiro constituiu o cenário ideal para as conquistas neoliberais no governo (MORAES, 2001).

As medidas neoliberais eram as mesmas do liberalismo, pois apenas ganhavam uma nova aparência. Os inimigos não eram mais o Estado Mercantilista e as corporações, mas, agora, o estado de bem-estar e os sindicatos (MORAES, 1997). Na afirmação de Moraes (2001), o objetivo ainda era diminuir as interferências do Estado, por meio de privatizações dos serviços públicos como saúde e educação, além de desregulamentar as relações de trabalho, por meio das noções de autonomia, gestão, assim como das contratações flexíveis e do salário proporcional ao desempenho.

O Estado deixa de ser responsável pelas decisões e passa a ter o papel de regulador que garante o cumprimento das regras necessárias para a sobrevivência do sistema capitalista, como no caso da manutenção das relações de trabalho, da propriedade privada e do sistema monetário (FRIEDMAN, 2014) ${ }^{2}$.

A busca pela expansão do mercado demandava a disseminação do discurso da globalização e da descrição de um cenário caótico nos países menos desenvolvidos, para que ocorresse uma internacionalização da exploração do trabalho e a implementação de reformas nos países subdesenvolvidos sob influência das potências mundiais (VIANA, 2008).

Desta forma, nos países da América-Latina, as reformas econômicas, políticas e sociais recebem forte influência dos organismos internacionais, como Banco Mundial, UNESCO, FMI, entre outros, principalmente no final do século XX e início do século XXI, de forma que suas ações são direcionadas para as políticas educacionais que são orientadas sob os ideais neoliberais. Os conceitos de mercado, eficiência e busca de resultados tornam-se o centro das ações educacionais, em detrimento da formação humana, pois " [...] os neoliberais enfatizam que a educação deve estar subordinada às necessidades do mercado de trabalho" (GENTILI, 1996), isto é, deve fornecer as ferramentas necessárias para o indivíduo competir, tornando-o capaz de adaptar-se às demandas do mercado.

\footnotetext{
${ }^{2}$ Milton Friedman (1912-2006) foi um dos economistas mais influentes do neoliberalismo, juntamente aos escritos de outros pensadores como Friedrich August Von Hayek (1899-1922) e James M. Buchanan (1919-2013).
} 
No Brasil, as recentes mudanças nas políticas educacionais - como a Reforma do Ensino Médio, a Base Nacional Comum Curricular, a política de formação dos professores, a Escola sem Partido e a PEC no 55/2016 - representam o desmonte de uma educação que buscava romper com as concepções conservadoras e elitistas (AZEVEDO; REIS, 2018).

As diferentes medidas educacionais tiveram forte impacto na formação dos indivíduos e, dentre os diversos exemplos que se colocam na atualidade, o foco desta análise será a Base Nacional Comum Curricular (BNCC) para a educação.

\section{As origens e o processo de formação da Base Nacional Comum Curricular}

O contexto atual apresenta um cenário de minimização dos direitos sociais, políticos e civis, em que a educação propõe um projeto que se distancia da formação humana e crítica e busca a formação da classe trabalhadora para a venda de sua força de trabalho qualificada. Entre as recentes medidas educacionais, citam-se a Reforma do Ensino Médio, a Base Nacional Comum Curricular, a Política Nacional de Formação de professores e a defesa de uma "Escola sem partido". Todas elas evidenciam o retrocesso que os brasileiros têm acompanhado e sofrido, principalmente pós-golpe 2016, com a presidência antidemocrática de Michel Temer, momento em que a perda de direitos e garantias dos trabalhadores começou a ser efetivada (AZEVEDO; REIS, 2018).

As medidas educacionais impactaram a formação dos indivíduos e, dentre os diferentes exemplos que se colocam na atualidade, o foco desta pesquisa está nos impactos das inúmeras medidas recentes da política educacional que refletiram a formação humana presente na Base Nacional Comum Curricular (BNCC). Silva et al. (2016) consideram que a aprovação desse documento foi uma ação de uma política antidemocrática que desconsiderou as sugestões dos professores e das universidades que discutiam as questões da formação e da aprendizagem (SILVA et al., 2016). Na análise de Azevedo e Reis (2018, p. 30), o objetivo foi formar um documento que embasasse toda a ação educacional dos municípios e dos estados e que seguisse os interesses da classe dominante, pois " [...] foi aprovada por um CNE alinhado com o governo Temer e MEC, em dezembro de 2017, com o voto contrário de três conselheiras comprometidas com a educação pública e com as entidades educacionais que representam”.

A declaração de Márcia Ângela Aguiar, em 2017, quanto a seu voto contrário à BNCC, expressava que o documento rompia com os significados da educação básica, pois excluía o ensino médio e minimizava a EJA. As propostas feriam o princípio da valorização das experiências extraescolares e desrespeitavam a pluralidade proposta pela Lei de Diretrizes e 
Bases da Educação Nacional vigente. A aprovação da BNCC pelo Conselho Nacional de Educação, com lacunas e incompletudes, representa uma abdicação de seu papel como órgão de Estado (BRASIL, 2017a). Além disto, o documento representou as transferências dos serviços públicos para o setor privado, devido à influência de movimentos empresariais (SILVA et al., 2016).

As parcerias com movimentos empresariais - como o Movimento pela Base Nacional Comum (MBNC) - demonstram a venda do setor público e a interferência das empresas privadas nas decisões educacionais do país. Esse movimento foi patrocinado pela Fundação Lemann em conjunto com outras instituições públicas e privadas, como UMDIME, CONSED, INEP, UnB, entre outras instituições públicas. As instituições particulares foram várias, dentre elas o Banco Itaú, a Natura, Diversa, Cesgranrio e, principalmente, as que produzem os materiais didáticos: Fundação Santilana e Abrelivros, Instituto Ayrton Senna, Insper e Fundação Roberto Marinho. Todas essas instituições, públicas ou privadas, constituem um grupo hegemônico que representa um projeto educacional para todo o país. As mudanças propostas pela BNCC demonstram o modelo de educação que a classe dominante busca. São as reformas fundamentadas nas ações internacionais que determinam os padrões curriculares a serem seguidos pelo país (AZEVEDO; REIS, 2018).

A presença de instituições que produzem materiais didáticos já indica os interesses implícitos nas parcerias estabelecidas com o Estado. A utilização desse mercado para a produção do lucro reflete nos currículos e conteúdos que serão implementados nas escolas. Segundo Alves (2011) as determinações didático-pedagógicas são estabelecidas pelas empresas privadas, cujos ideais convergem com os interesses neoliberais, facilitando a formação do consenso necessário à aceitação das condições de exploração, além da construção de um currículo que forme indivíduos capazes de se adaptar às modificações do mercado.

A participação de empresariados, como no caso da Fundação Lemann, reforça os princípios capitalistas a serem desenvolvidos na escola. A fundação é presidida por Jorge Paulo Lemann, capitalista brasileiro atuante no ramo das bebidas alcoólicas, dos alimentos (Burger King), do transporte ferroviário, das Lojas Americanas, entre outras. A Fundação Lemann tem como objetivo o desenvolvimento econômico do país, a partir da educação e de uma formação flexível e adaptável, em que o trabalhador seja capacitado e acompanhe os desenvolvimentos tecnológicos, qualificando a sua mão de obra (D’ÁVILA, 2013).

Os princípios defendidos por Lemann acompanham as indicações do Banco Mundial, o que se reflete na última versão da BNCC, já que a fundação teve forte participação em sua elaboração. A defesa do ensino médio e da EJA a distância é uma orientação do BM, que é 
mencionada no documento. A preocupação com a qualificação dos professores, para que sejam eficientes e gerem resultados, mas com o foco na educação básica que é mais viável economicamente (D’ÁVILA, 2013), é uma questão que também aparece na elaboração da BNCC e que trará fortes consequências para a educação, já que as estratégias do capital, nesse campo, visam apenas a ampliar os espaços de acumulação e não possibilitar uma formação humana dos indivíduos.

\section{As estruturas educacionais da BNCC e suas particularidades}

Com vistas a garantir o acesso e a permanência na escola, a estruturação de um patamar comum de aprendizagens é o objetivo principal da estruturação da Base Nacional Comum Curricular no governo brasileiro. Assim, a BNCC determina que a educação básica deve garantir a aprendizagem de competências gerais. No documento,

[...] competência é definida como a mobilização de conhecimentos (conceitos e procedimentos), habilidades (práticas, cognitivas e socioemocionais), atitudes e valores para resolver demandas complexas da vida cotidiana, do pleno exercício da cidadania e do mundo do trabalho (BRASIL, 2017b, p. 8).

Nessa perspectiva, o conhecimento está relacionado a habilidades necessárias que devem ser aplicadas, a fim de encontrar novas formas de ação que permitam uma adaptação dos indivíduos ao trabalho (MARSIGLIA et al. 2017). Além disto, o desenvolvimento dessas competências exige o "aprender a aprender" que consiste em:

[...] saber lidar com a informação cada vez mais disponível, atuar com discernimento e responsabilidade nos contextos das culturas digitais, aplicar conhecimentos para resolver problemas, ter autonomia para tomar decisões, ser proativo para identificar os dados de uma situação e buscar soluções, conviver e aprender com as diferenças e as diversidades (BRASIL, 2017b, p. 14).

As pedagogias que estão centradas nesse lema retiram da escola o papel de transmissão do conhecimento e secundarizam o papel do professor, além de retirar dos indivíduos o acesso à verdade (MARSIGLIA et al., 2017).

Para além das discussões sobre currículo dentro da BNCC, sua proposta discute o processo de ensino com enfoque no protagonismo do aluno. Os sentimentos, valores e crenças de cada indivíduo devem ser considerados dentro desse processo de ensino. De acordo com Marsiglia et al. (2017, p. 17), “[...] as escolas precisam elaborar propostas pedagógicas que considerem as necessidades, as possibilidades e os interesses dos estudantes, assim como suas identidades linguísticas, étnicas e culturais". 
Ao focalizar o desenvolvimento das competências e as necessidades individuais, o documento expressa a influência que recebe dos organismos internacionais, principalmente ao justificar a formação do indivíduo capaz de se adaptar ao mundo do trabalho. Além disso, a BNCC segue o modelo:

[...] adotado nas avaliações internacionais da Organização para a Cooperação e Desenvolvimento Econômico (OCDE), que coordena o Programa Internacional de Avaliação de Alunos (Pisa, na sigla em inglês), e da Organização das Nações Unidas para a Educação, a Ciência e a Cultura (Unesco, na sigla em inglês), que instituiu o Laboratório Latino-americano de Avaliação da Qualidade da Educação para a América Latina (LLECE, na sigla em espanhol) (BRASIL, 2017b, p. 14).

As determinações colocadas pelas empresas privadas com o discurso hegemônico da classe dominante influenciam a BNCC e retiram a característica de um currículo que deveria buscar a qualidade da educação. A defesa da relação público-privado, nos documentos internacionais, está refletida no processo de elaboração da BNCC, que contou com a participação de empresas privadas que objetivam a ampliação do capital e o desenvolvimento econômico (PERONI et al., 2017). As políticas educacionais provenientes da aliança entre os setores público e privado desconsideram os conteúdos necessários à formação humana, pois estruturam uma educação institucionalizada que, segundo Mészáros (2008, p. 35), tem “[...] o propósito de não só fornecer os conhecimentos e o pessoal necessário à maquinaria produtiva em expansão do sistema capitalista, mas também o de gerar e transmitir um quadro de valores que legitima os interesses dominantes [...]”.

O conhecimento que precisa ser focalizado na escola, como está expresso na BNCC, é o relativo às nossas experiências individuais. Nesta compreensão, os conhecimentos históricos, filosóficos e artísticos não possuem relevância. As produções culturais e o conhecimento realizado pelo homem no desenvolvimento do trabalho não são apropriados pelo indivíduo. Somente as competências necessárias à forma de trabalho presente são focalizadas, de forma que não é preciso a realização de atividades conscientes.

A nova proposta de educação expressa na BNCC precisa ser disseminada e implementada nas escolas. Assim, a União tem o papel de produzir uma forma de conhecimento comum que seja reproduzida pelos professores, diretores e universidades. Portanto,

A primeira tarefa de responsabilidade direta da União será a revisão da formação inicial e continuada dos professores para alinhá-las à BNCC. A ação nacional será crucial nessa iniciativa, já que se trata da esfera que responde pela regulação do ensino superior, nível no qual se prepara grande parte desses profissionais. Diante das evidências sobre a relevância dos professores e demais membros da equipe escolar para o sucesso dos alunos, essa é uma ação fundamental para a implementação eficaz da BNCC (BRASIL, 2017b, p. 22). 
O ensino superior formará professores a partir dos princípios e conhecimentos colocados na BNCC, cujo foco estará nas competências, no "aprender a aprender" e no protagonismo do estudante em sua aprendizagem. As modificações educacionais são realizadas de cima para baixo, de maneira que a União juntamente com as empresas privadas determinam os conhecimentos a serem ensinados.

\section{0 processo dinâmico das relações entre os conceitos neoliberais e a Base Nacional Comum Curricular}

As reformas econômicas, políticas e sociais nos países da América Latina recebem forte influência dos organismos internacionais e suas ações são direcionadas para as políticas educacionais que são orientadas sob os ideais neoliberais, cuja função educacional seria melhorar a capacidade dos indivíduos de utilizar recursos para produzir serviços e bens (OLIVEIRA, 2000). A escola é o meio de garantir o desenvolvimento de aptidões e habilidades que garantam a sobrevivência econômica do país.

Em consonância com o pensamento de Friedman (2014), um dos principais teóricos do neoliberalismo, um governo com princípios neoliberais deve tratar a educação enquanto instrução, na visão de uma formação prática de habilidades e competências que possam ser aplicadas na vida profissional ou no dia-a-dia. Além disso, assim como Smith, Friedman considera que, para que uma sociedade possa ser estável, necessita-se que haja um grau mínimo de alfabetização e de conhecimento por parte da classe trabalhadora.

Desta forma, a elaboração da Base Nacional Comum Curricular, que se fundamenta nos discursos do liberalismo econômico reproduzidos no neoliberalismo, explica a razão de o foco do documento estar nas competências, no individualismo e no aprender a aprender. A perspectiva defendida por Adam Smith e Friedman, isto é, a ideia de que o trabalhador tem de saber escrever, ler e contar minimamente, está nas entrelinhas da BNCC.

Um outro elemento importante nesse processo é a relação público-privado representada pelas parcerias estabelecidas com o Estado, principalmente, no âmbito educacional, como é o caso do Movimento pela Base Nacional Comum (MBNC) que caracteriza a interferência das empresas privadas nas decisões educacionais. Dentre tantos outros interesses neoliberais - como a elaboração de materiais didáticos enquanto meio de produção do lucro (AZEVEDO; REIS, 2018) - está, também, o propósito de "[...] formar professores pautados na teoria do capital humano de forma que, os futuros trabalhadores devem ser formados para garantir o processo de mundialização e acumulação de capital” (D’ÁVILA, 2013, p. 11566). 
O objetivo de contribuir para as modificações referentes "“[...] à formação de professores, à avaliação, à elaboração de conteúdos educacionais e aos critérios para a oferta de infraestrutura adequada para o pleno desenvolvimento da educação" (BRASIL, 2017b) representa as interferências neoliberais nas políticas do Estado e a adoção das recomendações do Banco Mundial, pois, de acordo com Alves (2011, p. 14), “O Brasil entregou a educação de seu povo ao modelo neoliberal do Banco Mundial".

A focalização do ensino fundamental também se dá por essas interferências, que priorizam o desenvolvimento de competências definidas como “[...] a mobilização de conhecimentos (conceitos e procedimentos), habilidades (práticas, cognitivas e socioemocionais), atitudes e valores para resolver demandas complexas da vida cotidiana, do pleno exercício da cidadania e do mundo do trabalho (BRASIL, 2017b, p. 8)”; esses conteúdos e objetivos convergem com as orientações de reformas dos organismos internacionais, principalmente o Banco Mundial, e constituem padrões curriculares a serem seguidos que, em última instância, pretendem sucatear a educação pública com a finalidade de privatizá-la, consolidando o projeto de submeter a educação ao mercado.

Por isso, há elementos basilares que expressam a conformação da BNCC com os princípios neoliberais, tais como a presença dos conceitos do mercado e a necessidade de formações técnicas, os quais serão tratados no tópico a seguir.

\subsection{O lema aprender a aprender}

O pressuposto pedagógico do "aprender a aprender", destacado numa série de documentos que sustentam leis, currículos, parâmetros, diretrizes, quando lido de forma aligeirada pode demonstrar - na aparência - que há uma proposta educacional democrática (DUARTE 2001; DUARTE, 1998). Todavia, a análise de sua essência, de sua substância histórica, remete aos princípios educacionais liberais preconizados por Adam Smith no século XVIII. Entende-se que o lema aprender a aprender reforça a ideia de Smith, no que se refere ao incentivo para as massas desenvolverem a capacidade de ler, escrever e contar minimamente.

O lema "aprender a aprender" destaca que o indivíduo deve ser estimulado para produzir ciência em vez de estudar a ciência já sistematizada, além de destacar que o indivíduo deve aprender a investigar e, desse modo, ele irá enriquecer sua cultura desde que haja um ambiente favorável. Com isso, o indivíduo aprende naturalmente, sem a intervenção sistemática do professor. Assim a educação pelo "aprender a aprender" coloca o indivíduo que aprende no centro do processo pedagógico, ao passo que o professor é considerado um sujeito 
complementar na relação ensino-aprendizagem. Dessa forma, o destaque excessivo dado ao processo pedagógico provoca o esvaziamento do conteúdo clássico a ser ensinado.

Há uma desvalorização do saber escolar, saber sistematizado, o qual exige a função precípua do professor, ou seja, o ensino da cultura clássica é desmerecido pelo pressuposto pedagógico do "aprender a aprender". O esvaziamento da cultura clássica no ensino faz com que o senso comum, o saber espontâneo, seja o mediador de relações pedagógicas, de maneira que há um empobrecimento na relação ensino-aprendizagem. Com isso, as políticas públicas, os parâmetros e as diretrizes, ao fundamentarem-se no pressuposto pedagógico do "aprender a aprender", cumprem a finalidade educacional para as massas conforme Smith apregoou.

Assim, na escola pública, as massas, os filhos da classe trabalhadora estarão lendo, escrevendo e contando minimamente. O ato de aprender não é fácil. Saviani (2014) discorre sobre o sujeito que está aprendendo a dirigir um carro. $\mathrm{O}$ ato de articular a força no pedal da embreagem com o pedal do acelerador é difícil, mas quando o sujeito se apropria desse conhecimento, a ação se torna automática.

Gramsci (1891-1937) ensina que aprender é doloroso. Não é uma atividade espontânea. Assim, o esvaziamento da cultura clássica associado à secundarização do ato de ensinar do professor com o "aprender a aprender" reforça a divisão de classes quando se observa que aqueles que serão educados para serem ordeiros e submissos não precisam se apropriar da cultura clássica. Cabe-lhes intensificar seu saber espontâneo e com isso intensificar o estranhamento em relação a si, o estranhamento em relação ao outro e em relação à realidade.

Dessa forma, as políticas educacionais fundamentadas no pressuposto aqui analisado intensificam a relação social regida pelo capital. Observa-se que todas as ações do Estado, inclusive em suas políticas educacionais, estão a serviço do capital, à medida que se estabelece legalmente a precarização do ensino, por meio de propostas pedagógicas que, ao pregarem o espontaneísmo, intensificam o obscurantismo dos indivíduos.

\subsection{As competências nas bases curriculares nacionais}

A noção de competência na educação está em consonância com as ideias do "aprender a aprender" e com sua respectiva fundamentação pedagógica, o neoconstrutivismo. Com isso, a partir da Conferência Mundial da Educação, em 1990, na Tailândia, com o apoio do Banco Mundial, o Brasil, ao participar desse evento, adota a noção de competências para orientar o Plano Decenal de Educação para todos (1993-2003). Os Parâmetros Curriculares Nacionais 
(PCNs) constituem-se como documento formulado no Brasil, a partir da conferência supracitada, tendo as competências como um dos conceitos norteadores desse documento.

Entretanto, a origem da noção de competência na educação pode datar da década de 1970, visto que, nesse momento, as relações sociais de produção entraram numa crise estrutural (MÉSZÁROS, 2008, ANTUNES, 2003). Essa crise estrutural revelou-se quando o Produto Interno Bruto (PIB) entrou em queda mundial, exceto no Japão, e o modelo de Estado de bemestar social deu sinais de esgotamento. A produção de capital e o trabalho entraram em crise conjuntamente.

Nesse contexto, os processos fordistas e tayloristas, com a separação entre aqueles que pensam e aqueles que executam a produção de mercadorias, foram colocados em xeque pelo processo toyotista. Os japoneses inseriram tecnologia na produção de mercadorias e formaram uma força de trabalho, na qual um sujeito deveria cumprir cerca de cinco funções que antes eram desempenhadas por vários indivíduos no processo fordista. Se um trabalhador colocava parafusos, outro colocava o banco, outro pintava, outro colocava a porta, ou seja, no processo fordista, o trabalho se desenvolvia em série; porém, com o Toyotismo um trabalhador executaria todas essas funções e, ainda, realizaria uma avaliação da produção com manuais de Controle de Qualidade. Assim, precisava-se de uma força de trabalho que além de ordeira e submissa também fosse competente. Dessa forma, essa noção de força de trabalho competente se expande como um modelo mundial. Afinal, intensifica-se cada vez mais a produção de mais mercadorias, com menos trabalhadores e em menos tempo.

Consequentemente, a crise estrutural do capital faz emergir a crise do desemprego estrutural. Nunca a noção de meritocracia foi tão destacada, afinal, as ideias predominantes propagam a visão de que a conquista do direito de receber um salário está diretamente condicionada ao mérito e à competência do sujeito. Nessa perspectiva, os desempregados são sujeitos sem qualificação, de modo que recai sobre o indivíduo a responsabilidade por não conquistar a condição de ser explorado, quando, na verdade, não há trabalho para todos os homens na sociedade.

No sistema produtivo capitalista, é com o trabalho que se produz mais valia e para expandir o capital é necessário aumentar a produtividade de cada trabalhador e estender sua jornada de trabalho (MARX, 1984). Os japoneses da Toyota perceberam muito bem as necessidades do capital e promoveram intervenções na produção, as quais propiciaram sua expansão naquele país, enquanto o mundo estava em crise.

Assim, os modelos educacionais alteraram-se no mundo para atender às novas demandas para a produção de mercadorias e expansão do capital. Os Estados Unidos e a 
Inglaterra foram os países pioneiros em reformas curriculares no ensino, realizando formações continuadas de professores e criando sistemas de avaliações para verificar se as novas metas educacionais para formar sujeitos competentes estavam sendo atendidas.

Desse modo, no Brasil, a noção de competências chegou na década de 1990 e foi retomada pelo governo Temer via educação, constituindo-se um dos princípios que alicerçam a BNCC.

\subsection{O aluno protagonista na aprendizagem das competências}

Na BNCC, as competências básicas são os conhecimentos a serem desenvolvidos no aluno, no processo de ensino. Entretanto, esse processo apresenta características especificas que têm como base os conceitos da modernidade e da pós-modernidade, especificamente, as teorias fenomenológicas.

Nagel et al. (2018) explicam que os discursos fenomenológicos se centralizam na liberdade pessoal, na subjetividade e na relatividade, além de ressaltarem a importância de o indivíduo concentrar-se na experiência do momento. As características de uma educação fenomenológica, que se centraliza nas experiências dos indivíduos e em suas percepções, representam os ideais da BNCC, pois, ao determinar os objetivos dos conhecimentos, o documento utiliza verbos como: interagir, respeitar, experimentar, refletir ou usufruir. Os verbos referem-se às ações dos indivíduos, a sua subjetividade e não ao que o professor deve possibilitar a esses alunos. Nessa concepção, o aluno compreende os conhecimentos, a partir de suas vivências e reflexões e não a partir dos conhecimentos científicos produzidos historicamente, apresentados por um professor.

A negação da ciência histórica ou naturalista, de acordo com Martineli (2013), deve-se à condição do método de ensino que apresenta uma abordagem a-histórica, já que a fenomenologia é constituída por significações que são construídas pelo nível empírico, ou seja, da experimentação. Por isso, a BNCC determina como uma de suas competências:

\footnotetext{
Valorizar e utilizar os conhecimentos historicamente construídos sobre o mundo físico, social, cultural e digital para entender e explicar a realidade, continuar aprendendo e colaborar para a construção de uma sociedade justa, democrática e inclusiva (BRASIL, 2017b, p.11).
}

A história e a constituição do conhecimento não são consideradas no documento, ou seja, é apenas o conhecimento pelo conhecimento. $\mathrm{O}$ aluno aprende o conteúdo sem ter acesso ao seu processo histórico, pois há a necessidade de uma redução fenomenológica que recomenda "[...] ao indivíduo que ele se abstenha de formular qualquer juízo que possa limitar 
a sua experiência pessoal" (NAGEL et al., 2018, p. 35). O conhecimento a ser aprendido pelo indivíduo também é submetido a uma redução transcendental que consiste na visão de um sujeito sem ser “[...] datado, real, empírico, social, histórico, mas, apenas, como uma consciência pura" (NAGEL et al., 2018, p. 35).

A educação é voltada para a formação social humana, para uma realização do ser estudante, propondo-se a tornar o indivíduo uma pessoa participativa na sociedade e capaz de atualizar suas habilidades (MARTINELI, 2015). Desta forma, a percepção de educação da BNCC caminha na mesma linha, pois considera que está " [...] deve afirmar valores e estimular ações que contribuam para a transformação da sociedade, tornando-a mais humana, socialmente justa e, também, voltada para a preservação da natureza" (BRASIL, 2017b, p. 8).

As políticas educacionais brasileiras permeadas pelos conceitos fenomenológicos representam a expressão de um neoliberalismo que anseia por uma educação cada vez mais individualista, em que cada indivíduo apresenta um significado para cada situação. A necessidade de formar o homem para viver em sociedade, nesta perspectiva, é apenas para transformá-lo em um sujeito produtivo que esteja adequado às condições do sistema capitalista. Afirmam Nagel et al. (2018, p. 52) que nessa nova educação “[...] rejeita-se a história, a cultura, as verdades universais, a possibilidade de progresso ou desenvolvimento". O mundo permanece da mesma forma, os sistemas não avançam e as modificações são feitas apenas para manter o sistema funcionando.

Por isso, de acordo com Marx (1984, p. 559), no mundo capitalista há o incentivo a uma educação com escolas de ensino profissional “[...] onde os filhos dos operários recebem algum ensino tecnológico e são iniciados no manejo prático dos diferentes instrumentos de produção", pois o trabalhador deve estar pronto para se adaptar às condições e às propostas de trabalho, isto é, deve ser um homem flexível e adaptável.

\section{Considerações finais}

A elaboração da Base Nacional Comum Curricular apresenta influência das instituições privadas e representa a predominância dessas instituições na estruturação das políticas e dos documentos educacionais brasileiros. Os interesses das empresas predominam na organização curricular da BNCC, que demonstra um currículo preocupado com a formação de competências necessárias ao mercado de trabalho, além da predominância de teorias fenomenológicas que produzem o individualismo, o conhecimento acrítico e a-histórico. 
Assim, ao analisar as interpretações da realidade e a visão de mundo adotada pelas políticas educacionais na atualidade, particularmente a BNCC aqui analisada, vê-se a predominância dos discursos neoliberais - sob influência de Smith e representada por Friedman, Hayek, entre outros - à medica que a política brasileira adota uma educação que atende aos interesses do capital e que se volta à formação do homem para o trabalho.

A classe dominante possui o discurso hegemônico e por isso, ao analisar a BNCC, é possível perceber os conceitos que vão ao encontro de seus interesses, tendo em vista a presença do aprender a aprender na perspectiva de desconsiderar os conhecimentos produzidos historicamente pelo homem e de secundarizar o trabalho do professor. Além disso, a presença de competências a serem desenvolvidas na escola expressa o discurso neoliberal de Friedman que defende a educação enquanto instrução. Por fim, o discurso da pós-modernidade - de que tudo é relativo e que a educação do trabalhador deve se direcionar aos apelos singulares em detrimento da totalidade e da compreensão da realidade completa - e a influência de um neoliberalismo, incentivador de liberdades individuais e de minimização de direitos sociais, além da diminuição de ações do Estado.

Apesar de as medidas educacionais como a BNCC serem um retrocesso, compreendese que vivemos em um sistema econômico atrasado, sendo este histórico e transitório, e que apesar de seus esforços para sobreviver, as condições materiais já estão postas e as relações já estão se modificando. A miséria e o máximo desenvolvimento das forças produtivas possibilitarão a formação de uma massa evolucionária consciente de sua ação.

\section{Referências}

ANTUNES, R. Os sentidos do trabalho. São Paulo: Boitempo, 2003.

ALVES, R. S. P. Neoliberalismo e educação: Uma década de intervenção do Banco Mundial nas políticas públicas no Brasil (2000-2010). In: SIMPÓSIO NACIONAL DE

HISTÓRIA, São Paulo. Anais do XXVI simpósio nacional da ANPUH - Associação Nacional de História. São Paulo: ANPUH, 2011. Disponível em: http://www.snh2011.anpuh.org/resources/anais/14/1300894657_ARQUIVO_artigoNE OLIBERALISMOEEDUCACAO.pdf

Acesso em: 01 ago. 2018.

AZEVEDO, J. C; REIS, J. T. Políticas Educacionais no Brasil Pós-Golpe. Porto Alegre: Editora Universitária Metodista IPA, 2018.

BRASIL. PARECER CNE/CP $N^{o}$ 15/2017. Proc. $N^{o}$ 23001.000201/2014-14. Brasília: Ministério da educação, 2017a. Disponível em: 
http://portal.mec.gov.br/index.php?option=com_docman\&view=download\&alias=78631pcp015-17-pdf\&category_slug=dezembro-2017-pdf\&Itemid=30192. Acesso em: 10 ago. 2018.

BRASIL. Base Nacional Comum Curricular. Brasília: Ministério da Educação, 2017b.

D’ÁVILA, J. L. Política De Formação Docente Executada Pelo Terceiro Setor: Considerações Sobre a Fundação Lemann. In: XI Congresso Nacional de Educação EDUCERE. Curitiba: ANAIS EDUCERE, 2013. Disponível em: http://educere.bruc.com.br/arquivo/pdf2013/10301_5770.pdf. Acesso em: 10 ago. 2018.

DUARTE, N. As pedagogias do "aprender a aprender" e algumas ilusões da assim chamada sociedade do conhecimento. Revista Brasileira de Educação. Rio de Janeiro, n. 18, 2001. Disponível em: http://www.scielo.br/pdf/rbedu/n18/n18a04.pdf. Acesso em: 08 out. 2018.

DUARTE, N. Concepções afirmativas e negativas sobre o ato de ensinar. Cadernos Cedes, v. 19, n. 44, p. 1-6, 1998. DOI: https://doi.org/10.1590/S0101-32621998000100008

ENGELS, F. A origem da Família, da Propriedade Privada e do Estado. 9. Ed. Rio de Janeiro: Civilização Brasileira, 1984.

FRIEDMAN, M. Capitalismo e Liberdade. São Paulo: LTC, 2014.

GENTILI, P. Neoliberalismo e educação: manual do usuário. In: SILVA, T. T. da; GENTILI, P. (Orgs.). Escola S.A.: quem ganha e quem perde no mercado educacional do neoliberalismo. Brasília, DF: CNTE, p. 9-49, 1996.

MARSIGLIA, A. C. G; PINA, L. D; MACHADO, V. O; LIMA, M. A Base Nacional Comum Curricular: Um novo episódio de esvaziamento da escola no Brasil. Germinal: Marxismo e Educação em Debate, Salvador, v. 9, n. 1, p. 107-121, abr. 2017. DOI: https://doi.org/10.9771/gmed.v9i1.21835

MARTINELI, T. A. P. A Fenomenologia nas concepções pedagógicas de João Paulo Medina e Vitor Marinho de Oliveira na Educação Física dos anos 1980. In: VIII CONGRESSO BRASILEIRO DE HISTÓRIA DA EDUCAÇÃO. Anais CBHE. Maringá, 2015.

MARTINELI, T. A. P. M. A educação física e a cultura no contexto da crise estrutural do capital: divergências teóricas e suas raízes filosóficas. 2013. Tese (Doutorado em Educação). Universidade Estadual de Maringá, Maringá, 2013.

MARX, K. Contribuições à crítica da Economia Política. 2. Ed. São Paulo: Martins Fontes, 1857.

MARX, K. O Capital: crítica da economia política. Livro 1 - O processo de produção do capital. São Paulo: Edifel, 1984.

MARX, K; ENGELS, F. A Ideologia Alemã. 5. Ed. São Paulo: Hucitec, 1986.

MÉSZÁROS, I. Para além do capital: rumo a uma teoria da transição. 1.ed. São Paulo: Boitempo, 2008. 
MORAES, R. C. Neoliberalismo - de onde vem, para onde vai? São Paulo: SENAC, 2001.

MORAES, R. C. Liberalismo e Neoliberalismo - Uma Introdução Comparativa. In: SEMANA DE CIÊNCIAS SOCIAIS DA FACULDADE DE FILOSOFIA, CIÊNCIAS E LETRAS. Palestra. Santo André, 1997. Disponível em:

https://reginaldomoraes.files.wordpress.com/2011/06/lib_neolib_compara.pdf. Acesso em: 19 ago. 2018.

NAGEL, L. H; CARAVALHO, E. J. G; MACHADO, M. C. G. Bases Teóricas e Práticas da Educação Brasileira. Maringá: EDUEM, 2018.

PAULO NETTO, J. Introdução ao método da teoria social, 2009. Palestra. Disponível em: http://pcb.org.br/portal/docs/int-metodo-teoria-social.pdf. Acesso em: 28 mai. de 2018.

OLIVEIRA, D. A. A Educação básica e profissional no contexto das reformas dos anos 90. In: $23^{\circ}$ Reunião Anual da Associação Nacional de Pós-Graduação e Pesquisa em Educação ANPED, Minas Gerais. ANAIS ANPED, 2000.

PERONI, V; CAETANO, M. R. C; LIMA, P. Reformas educacionais de hoje: As implicações para a democracia. Retratos da Escola. Brasília, v. 11, n. 21, p. 377-757, 2017.

DOI: https://doi.org/10.22420/rde.v11i21.793

ROSA, D. B. A. R. As ideias defendidas por Adam Smith para a educação: suas influencias nas orientações curriculares da educação básica do estado de Mato Grosso. In: XII Congresso Nacional de Educação- EDUCERE. Curitiba: ANAIS EDUCERE, 2015. Disponível em: https://educere.bruc.com.br/arquivo/pdf2015/16386_7397. PDF. Acesso em: 26 mai. De 2018.

SAVIANI, D. História das Ideias Pedagógicas no Brasil. Campinas: Editora Autores Associados, 2014.

SILVA, M. R; PIRES, G. L; PEREIRA, R. S. A Base Nacional Comum Curricular da Educação Básica em tempos de neoconservadorismo e de "neoliberalismo que saiu do armário"; mas também de tempos de resistência: Fora Temer!!! Motrivivência. Florianópolis, v. 28, n. 28, p. 7-14, 2016. Disponível em:

https://periodicos.ufsc.br/index.php/motrivivencia/article/view/2175-

8042.2016v28n48p7/32530. Acesso em: 19 ago. 2018.

SMITH, A. A Riqueza das Nações: Investigações Sobre sua Natureza e suas Causas. São Paulo: Abril Cultural, 1996.

TAUILE, J. R; FARIA, L. A. E. F. As transformações do capitalismo contemporâneo e sua natureza na análise de Marx. Revista de Economia Política. São Paulo, n. 19, n. 73, 1999. Disponível em:

https://lume.ufrgs.br/bitstream/handle/10183/24342/000008537.pdf?sequence=1\&isAllowed= y. Acesso em 25 mai. 2018.

VIANA, N. Breve História do Neoliberalismo. Revista Enfrentamento, n. 05, jul./ dez., 2008. 